Results: We were able to examine 91 AAV patients (52 MPA patients and 39 GPA patients) with $82.4 \%$ for MPO-ANCA positive and $20.9 \%$ for PR3-ANCA positive. Almost half of the patients was female (56.0\%). The median age was 70 years [interquartile range (IQR): 64-77]. The median BVAS was 17 (IQR: 12-23). We identified autoantigen of EGF-containing fibulin-like extracellular matrix protein 1 (EFEMP1) in 43 of MPA (82.6\%) and 16 of GPA (41.0\%) at baseline. After 6 months of treatment, no cases of EFEMP1 were identified in MPA and GPA. The clinical features of EFEMP1 positive in AAV patients were higher age at onset ( $p<0.01$ ), less ear, nose and throat symptoms at initiation of treatment $(p<0.05)$, higher serum $\mathrm{Cr}$ at initiation of treatment $(p<0.01)$, higher vasculitis damage index (VDI) renal component at 12 months and 24 months after initiation of treatment (both $\mathrm{p}<0.05$ ).

Conclusion: Our findings indicate that an autoantigen as immune complexes of EFEMP1 were involved in the pathogenesis of AAV patients and may predict renal prognosis.

References:

[1] Wilde B et.al, Kidney Int. 2011 Mar;79(6):599-612.

[2] Falk RJ et.al, J Am Soc Nephrol. 1997 Feb;8(2):314-22.

[3] Haas M et.al, Kidney Int. 2004 Jun;65(6):2145-52.

Table. Comparison with and without EFEMP1 (all cases)

\begin{tabular}{lccr}
\hline group & EFEMP1 positive $(\mathrm{n}=59)$ & EFEMP1 negative $(\mathrm{n}=32)$ & ${ }^{* *}$-value \\
\hline Sex $(\%$ male) & $27 / 59(45.8 \%)$ & $13 / 32(40.6 \%)$ & 0.665 \\
Age, years & $74(66-78)$ & $68(60-71)$ & 0.003 \\
WBC $(/ \mathrm{ml})$ & $8270(7325-12725)$ & $9150(7325-11700)$ & 0.280 \\
Cr(mg/dl) & $1.4(0.9-3.8)$ & $0.8(0.6-1.5)$ & 0.005 \\
CRP(mg/dl) & $7.0(2.3-12.5)$ & $7.6(4.0-11.0)$ & 0.566 \\
MPA(\%) & $43 / 59(72.9 \%)$ & $9 / 32(28.1 \%)$ & $<0.001$ \\
GPA(\%) & $16 / 59(27.1 \%)$ & $23 / 32(71.9 \%)$ & $<0.001$ \\
MPO-ANCA positive & $54 / 59(91.5 \%)$ & $24 / 32(65.6 \%)$ & 0.003 \\
PR3-ANCA positive* & $7 / 56(12.5 \%)$ & $12 / 32(37.5 \%)$ & 0.012 \\
BVAS total & $15(12-20)$ & $20(12-25)$ & 0.087 \\
BVAS renal positive & $53 / 59(89.8 \%)$ & $26 / 32(81.3 \%)$ & 0.332 \\
BVAS chest positive & $16 / 59(27.1 \%)$ & $14 / 32(43.4 \%)$ & 0.161 \\
BVAS ENT positive & $17 / 59(28.8 \%)$ & $18 / 32(56.3 \%)$ & 0.014 \\
BVAS systemic positive & $40 / 59(67.8 \%)$ & $24 / 32(75.0 \%)$ & 0.631 \\
VDI renal 6 months & $1(0-2)$ & $0(0-1)$ & 0.053 \\
VDI renal 12 months & $1(0-2)$ & $0(0-1)$ & 0.007 \\
VDI renal 24 months & $1(0-2)$ & $0(0-1)$ & 0.012 \\
\end{tabular}

IQR interquartile range. Values are median(IQR) or $n(\%),{ }^{*}$ missing data, ${ }^{*}$ Wilcoxon signedrank test/Fisher's exact test

Disclosure of Interests: Momoko Okamoto: None declared, Kunihiro Ichinose: None declared, Kaname Oyama: None declared, Ken-Ei Sada: None declared, Shin-ya Kaname: None declared, masayoshi harigai Grant/research support from: AbbVie Japan GK, Ayumi Pharmaceutical Co., Bristol Myers Squibb Co., Ltd., Eisai Co., Ltd., Mitsubishi Tanabe Pharma Co., Nippon Kayaku Co., Ltd., and Teijin Pharma Ltd. MH has received speaker's fee from AbbVie Japan GK, Ayumi Pharmaceutical Co., Boehringer Ingelheim Japan, Inc., Bristol Myers Squibb Co., Ltd., Chugai Pharmaceutical Co., Ltd., Eisai Co., Ltd., Eli Lilly Japan K.K., GlaxoSmithKline K.K., Kissei Pharmaceutical Co., Ltd., Oxford Immuotec, Pfizer Japan Inc., and Teijin Pharma Ltd. MH is a consultant for AbbVie, Boehringer-ingelheim, Kissei Pharmaceutical Co., Ltd. and Teijin Pharma., Atsushi Kawakami: None declared

DOI: 10.1136/annrheumdis-2020-eular.2705

\section{THU0316 VALIDATION OF ACR/EULAR PROVISIONAL CLASSIFICATION CRITERIA FOR ANCA-ASSOCIATED VASCULITIS IN A LATIN-AMERICAN TERTIARY CENTER}

V. Pimentel-Quiroz ${ }^{1,2}$, A. Sánchez-Torres ${ }^{1}$, C. Reategui Sokolova ${ }^{1,3}$, R. V. Gamboa Cárdenas ${ }^{1}$, C. Sánchez-Schwartz ${ }^{1}$, M. Medina Chinchon ${ }^{1}$, F. Zevallos Miranda ${ }^{1}$, E. Noriega ${ }^{1}$, J. Alfaro Lozano ${ }^{1}$, J. M. Cucho-V ${ }^{1}$, Z. Rodriguez Bellido ${ }^{1,4}$, C. Pastor Asurza ${ }^{1,4}$, E. Acevedo-Vásquez ${ }^{1,4}$, R. Perich Campos ${ }^{1,4}$, G. S. Alarcon ${ }^{5,6}$, M. F. Ugarte-Gil ${ }^{1,2} .{ }^{1}$ Hospital Nacional Guillermo Almenara Irigoyen, Rheumatology, LIma, Peru; ${ }^{2}$ Universidad Científica del Sur, Lima, Peru; ${ }^{3}$ Universidad San Ignacio de Loyola, Unidad de Investigación para la Generación y Síntesis de Evidencias en Salud, Lima, Peru; ${ }^{4}$ Universidad Nacional Mayor de San Marcos, Lima, Peru; ${ }^{5}$ University of Alabama at Birmingham, Division of Clinical Immunology and Rheumatology, Department of Medicine, School of Medicine, Birmingham, United States of America; ${ }^{6}$ Universidad Peruana Cayetano Heredia, Medicina, Lima, Peru

Background: There is lack studies about performance of new criteria set for ANCA-Associated Vasculitis (AAV) in Latin-America.
Objectives: To validate the new classification criteria for AAV in a real-life cohort of patients with these conditions.

Methods: We performed a review of medical records from January 1990 to December 2019 at Hospital Nacional Guillermo Almenara Irigoyen from Peru. AAV was diagnosed by experienced rheumatologists based on the ACR 1990 criteria, Chapel Hill 2012 consensus, EMEA criteria and their experience and clinical acumen. Granulomatosis with polyangiitis (GPA), microscopic polyangiitis (MPA) and eosinophilic granulomatosis with polyangiitis (EGPA) were diagnosed. Renal limited vasculitis was considered as MPA. To evaluate the performance of the new criteria, we classified all patients using "former criteria set" (including the 1990 ACR criteria for GPA and EGPA and the 1994 Chapel Hill Consensus Conference for MPA) and the EMEA (European Medicines Agency) criteria set. At the same time, we classified all patients using the ACR/EULAR Provisional criteria (new criteria set). The values for sensitivity, specificity and level of agreement (using Cohen's kappa) of all sets of criteria were calculated using the clinical diagnosis as gold standard.

Results: Two hundred twelve patients were identified; 12 of them were excluded (eight did not have ANCA and four had incomplete data). Female/male ratio was $1.9: 1[130(65 \%) / 70(35 \%)]$ and their mean (SD) age at diagnosis was $59.3(12.6)$ years. One hundred fifty-four (77\%) had MPA, $41(20.5 \%)$ GPA and $5(2.5 \%)$ EGPA. One hundred ninety-six patients had ANCA-IIF results [p-ANCA: 131 (66.8\%), c-ANCA: 43 (21.9\%), negative-ANCA: 22 (11.3\%)] and 190 patients had ANCA-ELISA results [MPO: 129 (67.9\%), PR3: 37 (19.5\%), negative-ANCA: 24 (12.6\%)]. Type of diagnosis according to criteria set used is depicted in Table 1. The new criteria set had better agreement (kappa: 0.653) than the EMEA criteria (kappa: 0.506) and the former criteria set (kappa: 0.305). Performance of the criteria sets is depicted in Table 2.

Table 1. Type of AAV according to criteria set used.

\begin{tabular}{lcccc}
\hline TYPE OF AAV & Clinical diagnosis & Former criteria & New criteria & $\begin{array}{c}\text { EMEA } \\
\text { criteria }\end{array}$ \\
\hline MPA, $\mathbf{n}(\%)$ & $154(77)$ & $76(38)$ & $137(68.5)$ & $110(56.0)$ \\
GPA, $\mathbf{n}(\%)$ & $41(20.5)$ & $30(15)$ & $39(19.5)$ & $39(19.5)$ \\
EGPA, $\mathbf{n}(\%)$ & $5(2.5)$ & $2(1)$ & $4(2)$ & $2(1.0)$ \\
Not classifiable, n (\%) & NA & $92(46)$ & $20(10)$ & $44(22.0)$ \\
PAN & & & & $5(2.5)$
\end{tabular}

PAN: Polyarteritis nodosa. NA: Not applicable.

Table 2. Performance of the different criteria sets in AAV patients.

\begin{tabular}{lllll}
\hline DIAGNOSIS & CRITERIA SET & SE & SP & Kappa \\
\hline MPA & Former & 49.4 & 100.0 & 0.309 \\
& EMEA & 69.9 & 93.9 & 0.471 \\
GPA & New & 87.0 & 93.5 & 0.713 \\
& Former & 68.3 & 98.7 & 0.744 \\
\multirow{2}{*}{ EGPA } & EMEA & 92.7 & 99.4 & 0.938 \\
& New & 80.5 & 96.2 & 0.781 \\
& Former & 40.0 & 100.0 & 0.565 \\
& EMEA & 40.0 & 100.0 & 0.565 \\
& New & 60.0 & 99.5 & 0.659 \\
\hline
\end{tabular}

SE: Sensitivity. SP: Specificity.

Conclusion: The ACR/EULAR Provisional Criteria for AAV have better agreement with the clinical diagnosis of $A A V$ in Latin-American patients from a real-life cohort.

Disclosure of Interests: Victor Pimentel-Quiroz: None declared, Alfredo Sánchez-Torres: None declared, Cristina Reategui Sokolova: None declared, Rocío Violeta Gamboa Cárdenas Grant/research support from: Pfizer, César Sánchez-Schwartz: None declared, Mariela Medina Chinchon: None declared, Francisco Zevallos Miranda: None declared, Erika Noriega: None declared, Jose Alfaro Lozano Speakers bureau: Lilly, Jorge-M Cucho-V: None declared, Zoila Rodriguez Bellido: None declared, Cesar Pastor Asurza: None declared, Eduardo Acevedo-Vásquez: None declared, Risto Perich Campos Consultant of Pfizer, Speakers bureau: Pfizer, Graciela S Alarcon: None declared, Manuel F. Ugarte-Gil Grant/research support from: Jannsen, Pfizer DOI: 10.1136/annrheumdis-2020-eular.5092

\section{\begin{tabular}{|l|l}
\hline THU0317 EXPANDED DOUBLE NEGATIVE T CELLS IN \\
\hline
\end{tabular} PATIENTS WITH ANTINEUTROPHIL CYTOPLASMIC AUTOANTIBODY ASSOCIATED VASCULITIS PRODUCE CYTOKINES AND INDUCE RENAL DAMAGE}

Y. Qin ${ }^{1}$, J. Luo ${ }^{2}$, Y. Wang ${ }^{1}$, C. Gao ${ }^{3} .{ }^{1}$ The Second Hospital of Shanxi Medical University, Taiyuan, China; ${ }^{2}$ The Second Hospital of Shanxi Medical University, 